\title{
Transpleural versus extrapleural approach in treatment of esophageal atresia
}

\author{
Mohamed Batikhe(D)
}

\begin{abstract}
Background: Surgery is the only curative treatment of patients with esophageal atresia and tracheoesophageal fistula. A lot of surgeons recommend transpleural repair while others prefer extrapleural approach for repair. This study will evaluate the differences, advantages, outcome, and the disadvantages of the two techniques.

Results: Duration of surgery was significantly shorter in the group operated by transpleural approach. The incidence of pneumothorax was higher in patients operated by transpleural approach.

Conclusion: Operating esophageal atresia and tracheoesophageal fistula by transpleural approach has significantly shorter time of surgery, but there is no difference between the two groups as regards incidence of leakage or mortality.

Keywords: Extrapleural, Transpleural, Esophageal atresia
\end{abstract}

\section{Background}

Esophageal atresia and tracheoesophageal fistula is a congenital disease that occurs due to a defect in separating esophagus and trachea at the 5th week of pregnancy [1]. Surgical repair is the only definitive treatment with good outcome in the majority of the patients [2]. Right posterolateral thoracotomy through extrapleural approach at 4th intercostal space is a common technique of surgery [1]. Although it is difficult and needs much time to dissect pleura from chest wall, most of the surgeons prefer this approach more than transpleural technique, because the belief that empyema has less incidence if anastomotic leakage takes place, On the other hand, many surgeons believe that the outcome of the two techniques is the same while surgery by transpleural technique may be done more easy and faster [3].

\section{Objectives}

The objective of the study is to compare the extra pleural approach versus transpleural approach in treatment of esophageal atresia and tracheoesophageal fistula.
Correspondence: mohkhezawy@yahoo.com

Pediatric Surgery Unit, Sohag University, Sohag, Egypt

\section{Methods}

This prospective study included 20 patients with esophageal atresia and tracheoesophageal fistula who underwent repair in the period from January 2016 to January 2017 at pediatric surgery unit, Surgery Department, Sohag University Hospital, Sohag, Egypt. Ethics committee approval was obtained. Neonates suffering from esophageal atresia and tracheoesophagial fistula type $\mathrm{C}$ were enrolled in this study, we divided patients randomly into two groups; surgery was done by extrapleural approach in group a, and in group b, we used transpleural one. In all patients, steps are standardized: posterolateral thoracotomy, ligation of the tracheoesophageal fistula, mobilization of proximal pouch, and in all patients, anastomosis is done by vicryl $5 / 0$ interrupted sutures. In all patients, ryle feeding is started on the 3rd postoperative day and ryle is removed on the 7th day to start oral feeding. Chest tube and wound were evaluated by the surgeon regularly for any discharge and wound infection. Routine contrast study of the esophagus for possibility of leakage of the anastomosis was performed in all cases on the 5th postoperative day. The patients in both procedures were discharged after removal of the chest tube.

The 2 procedures were compared for the incidence of postoperative complications (anastomotic leakage, wound infection and disruption, pneumothorax, empyema, hydrothorax, lung collapse, and mortality), duration 
of surgery (starting from incision to closure of the skin), and hospitalization period (from admission day to discharge day). Neonates with weight less than 2000 g, patients with major heart anomalies, and patients with esophageal anomalies type other than C (A, B, D, E) were excluded from the study.

\section{Results}

Twenty neonates were enrolled in this study, and 12 (60\%) of whom surgery was done by extrapleural approach and $8(40 \%)$ by transpleural approach with demographic data summarized in Table 1. Associated anomalies are detected in $50 \%$ of cases (Table 2).

The duration of surgery was significantly shorter in the group operated by transpleural approach (Table 3), and two patients suffered from pneumothorax on the right side after surgery; all cases were operated by transpleural approach and all improved after insertion of intercostal tube under water seal, left-sided pneumothorax occurred in one patient in extrapleural group who was under mechanical ventilation and responded to intercostal tube insertion. The incidence of pneumothorax was statistically higher in patients operated by transpleural approach as compared to the extrapleural group (Table 4).

Two (10\%) patients developed leakage of anastomosis, $1(12.5 \%)$ of whom was in the transpleural group and 1 (8.3) was in the extrapleural group. The patient in extrapleural group with anastomotic leakage responded well to TPN and antibiotic therapy within 2 weeks. The one in the transpleural group had a major leak and feeding gastrostomy and esophagostomy was done, and the patient died on the 12th postoperative day due to neonatal sepsis (Table 4).

Two patients (10\%) died after surgery one $(12.5 \%)$ of whom was in the transpleural group (due to sepsis following major leakage) and one (8.3) was in the extrapleural group (delayed recovery from anesthesia and cardiac

Table 1 Comparison between the studied groups regarding age and sex

\begin{tabular}{llll}
\hline Characteristics & Extrapleural $(N=12)$ & Transpleural $(N=8)$ & $P$ value \\
\hline Sex & $5(41.7 \%)$ & $4(50 \%)$ & 1 \\
Female & $7(58.3 \%)$ & $4(50 \%)$ & \\
Male & & $0.514^{*}$ \\
Age at presentation (days) & $1.88 \pm 0.84$ & \\
Mean \pm S.D. & $2.17 \pm 0.94$ & $2(1-3)$ & $0.093^{*}$ \\
Median (range) & $2(1-4)$ & & \\
Age at surgery (days) & $2.13 \pm 0.64$ & \\
Mean \pm S.D. & $2.67 \pm 0.78$ & $2(1-3)$ & \\
Median (range) & $3(1-4)$ &
\end{tabular}

$P$ value is calculated by Fisher's exact test

* $P$ value is calculated by Mann-Whitney $U$ test
Table 2 Comparison between the groups regarding associated anomalies

\begin{tabular}{llll}
\hline Previous surgery & $\begin{array}{l}\text { Extrapleural } \\
(N=12)\end{array}$ & $\begin{array}{l}\text { Transpleural } \\
(N=8)\end{array}$ & $P$ value \\
\hline No anomalies & $7(58.3 \%)$ & $3(37.5 \%)$ & 0.229 \\
Coronal hypospadias & $0(0.0 \%)$ & $1(12.5 \%)$ & \\
Ectopic right kidney & $0(0.0 \%)$ & $1(12.5 \%)$ & \\
PDA & $0(0.0 \%)$ & $2(25 \%)$ & \\
Polydactyly & $1(8.3 \%)$ & $0(0.0 \%)$ & \\
Vestibular anus & $1(8.3 \%)$ & $0(0.0 \%)$ & \\
VSD & $3(25 \%)$ & $1(12.5 \%)$ & \\
\hline
\end{tabular}

$P$ value is calculated by Chi-Square test

arrest). No statistically important difference was observed as regards mortality between the two approaches (Table 4).

\section{Statistical analysis}

Data was analyzed using SPSS version 17. Quantitative data was expressed as means \pm standard deviation, median, and range. Qualitative data was expressed as number and percentage. The data were tested for normality using Shapiro-Wilk test. The nonparametric MannWhitney test was used for data which was not normally distributed.

Independent samples $T$ test was used for normally distributed data. Chi-square $\left(\chi^{2}\right)$ test and Fisher's exact test were used for comparison regarding qualitative variables as appropriate. A 5\% level was chosen as a level of significance in all statistical tests used in the study.

\section{Discussion}

The popularity of operating by the extrapleural approach is more than the transpleural approach because there is a belief between pediatric surgeons that there is increased incidence of empyema following leakage in the transpleural approach, we had no cases of empyema in our study neither in the tanspleural or the extrapleural group but we noticed that the patient with leakage in

Table 3 Comparison between the studied groups regarding hospital stay and duration of surgery

\begin{tabular}{lcll}
\hline Characteristics & $\begin{array}{l}\text { Extra pleural } \\
(N=12)\end{array}$ & $\begin{array}{l}\text { Transpleural } \\
(N=8)\end{array}$ & $P$ value \\
\hline Duration of surgery & (minutes) & & \\
Mean \pm S.D. & $130.33 \pm 8.69$ & $108.62 \pm 7.89$ & $<0.001$ \\
Median (range) & $130(118-145)$ & $109.5(100-120)$ & \\
Hospital stay (days) & & $15.75 \pm 0.71$ & $0.752^{*}$ \\
Mean \pm S.D. & $14.67 \pm 4.25$ & $16(15-17)$ & \\
Median (range) & $15.5(2-18)$ & &
\end{tabular}

$P$ value is calculated by independent samples $T$ test

${ }^{*} P$ value is calculated by Mann-Whitney $U$ test 
Table 4 Comparison between the studied groups regarding complications

\begin{tabular}{|c|c|c|c|}
\hline Characteristics & $\begin{array}{l}\text { Extra pleural } \\
(N=12)\end{array}$ & $\begin{array}{l}\text { Transpleural } \\
(N=8)\end{array}$ & $P$ value \\
\hline \multicolumn{4}{|l|}{ Leakage } \\
\hline No & 11 (91.7\%) & 7 (87.5\%) & 1 \\
\hline Yes & 1 (8.3\%) & 1 (12.5\%) & \\
\hline \multicolumn{4}{|l|}{ Pneumothorax } \\
\hline No & $11(91.7 \%)$ & $6(75 \%)$ & 0.537 \\
\hline Yes & 1 (8.3\%) & $2(25 \%)$ & \\
\hline \multicolumn{4}{|c|}{ Wound infection } \\
\hline No & $10(83.3 \%)$ & $6(75 \%)$ & 1 \\
\hline Yes & $2(16.7 \%)$ & $2(25 \%)$ & \\
\hline \multicolumn{4}{|l|}{ Mortality } \\
\hline No & 11 (91.7\%) & 7 (87.5\%) & 1 \\
\hline Yes & 1 (8.3\%) & $1(12.5 \%)$ & \\
\hline
\end{tabular}

$P$ value is calculated by Fisher's exact test

the extrapleural group responded will to conservative treatment within few weeks $(2,3)$.

The incidence of pneumothorax in our study was $15 \%$, which occurred in $25 \%$ of transpleural group and was right-sided (related to the operative procedure) and occurred in $8.3 \%$ of the extrapleural group and was leftsided (related to high pressure postoperative ventilation). All cases responded to intercostal tube insertion; in another similar study, the incidence of pneumothorax was $20 \%$ with all cases occurred in transpleural group [4].

The incidence of leakage of anastomosis in the textbooks of pediatric surgery ranged from 14 to $16 \%$, and in other studies, it was $10-20 \%$. In our study, leakage occurred in $2(10 \%)$ cases, in which one case improved on conservative treatment (operated by extrapleural approach), while the other case in transpleural group did not respond to conservative treatment. Redo surgery was done (esophagostomy and gastrostomy), but there was no statistical difference between the two groups as regards the incidence of leakage [4-7].

In the literature, mortality rate depends on the type of atresia, prematurity, aspiration pneumonia, and severe cardiac anomaly. In this study, we excluded premature neonates, neonates weighing less than $2000 \mathrm{~g}$ and patients with cyanotic heart anomaly; moreover, some authors concluded that anesthesia and postoperative intensive care may also have a role in survival of the patients, and we had a mortality rate $10 \%$ with no statistical difference between the two groups [8].

In our study, duration of surgery was significantly shorter in patients operated by transpleural technique due to the time needed for gentle detachment of the pleura from the chest wall in extrapleural approach, but actually, we need a larger study to evaluate the superiority of extrapleural approach in promoting spontaneous closure if leakage occurs.

\section{Conclusion}

There is no significant statistical difference between these two methods of surgery as regards mortality; however, there was a higher rate of pneumothorax in transpleural approach, while the duration of operation was shorter in surgery by transpleural approach, so we recommend transpleural approach if the patient is unstable and prolonged anesthesia carries a high risk.

\section{Acknowledgements \\ Not applicable.}

\section{Authors' contributions}

Not applicable. The author read and approved the final manuscript.

Funding

Not applicable.

\section{Availability of data and materials \\ Available upon request.}

\section{Ethics approval and consent to participate}

This study was approved by the Research Ethics Committee of the Faculty of Medicine at Sohag University in Egypt on 13 September 2015; Reference Number of approval F 14. Written informed consent of all patients for their participation was given by their parent or legal guardian.

\section{Consent for publication}

Not applicable.

\section{Competing interests}

The author declares that he/she has no competing interests.

Received: 13 December 2019 Accepted: 23 December 2019

Published online: 18 February 2020

\section{References}

1. O'Neill JA, Grosfeld JL, Fonkalsrud EW, et al. Principles of pediatric surgery. 6th edition. Philadelphia:Mosby; 2006; 573-586.

2. Hackam DJ, Newman K, Ford HR. Pediatric Surgery. In: F. Charles Brunicardi, Dana K. Anderson, Timothy R. Billiar, et al. Schwartz's principles of surgery, 8th ed. New York: McGraw-Hill 2005; p.1481-1485.

3. Oldham KT, Colombani PM, Foglia RP, et al. Principles and practice of pediatric surgery. Philadelphia: Lippincott Williams \& Wilkins; 2005. p. 1039-53.

4. Shahnam A, Nasrollah O, Amin B, Shahnam CA, Nasrollah O, Amin B. Evaluation of two surgical methods (Extrapleural and Transpleural) in the treatment of neonates with esophageal atresia. Internet J Surg. 2008;21:2.

5. McKinnon $L$, Kosloske AM. Prediction and prevention of anastomotic complications of esophageal atresia and tracheoesophageal fistula. J Pediatric Surg. 1990;25(7):778-81.

6. Villegas-Alvares F, Olvera-Duran J, Rodriguez-Aranda E, et al. Esophageal anastomotic failure: an experimental study. Arch Med Res. 2003;34:171.

7. Yanchar NL, Gordon R, Cooper M, et al. Significance of the clinical course and early upper gastrointestinal studies in predicting complications associated with repair of esophageal atresia. J Pediatr Surg. 2001;36:815.

8. Spitz L, Kiely EM, Morecroft JA, Drake DP. Esophageal atresia: at-risk groups for the 1990s. J Pediatr Surg. 1994;29:723.

\section{Publisher's Note}

Springer Nature remains neutral with regard to jurisdictional claims in published maps and institutional affiliations. 